\title{
Besifloxacin: A Critical Review of Its Characteristics, Properties, and Analytical Methods
}

\section{Eliane Gandolpho Tótoli \& Hérida Regina Nunes Salgado}

To cite this article: Eliane Gandolpho Tótoli \& Hérida Regina Nunes Salgado (2018) Besifloxacin: A Critical Review of Its Characteristics, Properties, and Analytical Methods, Critical Reviews in Analytical Chemistry, 48:2, 132-142, DOI: $10.1080 / 10408347.2018 .1429885$

To link to this article: https://doi.org/10.1080/10408347.2018.1429885

Accepted author version posted online: 18 Jan 2018.

Published online: 02 Feb 2018.

Submit your article to this journal ¿

Џ Article views: 117

Citing articles: 1 View citing articles 


\title{
Besifloxacin: A Critical Review of Its Characteristics, Properties, and Analytical Methods
}

\author{
Eliane Gandolpho Tótoli and Hérida Regina Nunes Salgado (D) \\ School of Pharmaceutical Sciences, UNESP - Universidade Estadual Paulista, Araraquara, São Paulo, Brazil
}

\begin{abstract}
Bacterial conjunctivitis has high impact on the health of the population, since it represents more than a third of ocular pathologies reported by health services worldwide. There is a high incidence of bacterial resistance to the antimicrobials most commonly used for the treatment of conjunctivitis. In this context, besifloxacin stands out, since it is a fluoroquinolone developed exclusively for topical ophthalmic use, presenting a low risk of developing resistance due to its reduced systemic exposure. Bausch \& Lomb markets it as ophthalmic suspension, under the trade name Besivance ${ }^{\mathrm{TM}}$. Literature review on besifloxacin is presented, covering its pharmaceutical and clinical characteristics, and the analytical methods used to measure the drug in pharmaceutical products and biological samples. High performance liquid chromatography is the most used method for this purpose. A discussion on Green Chemistry is also presented, focusing the importance of the development of green analytical methods for the analysis of drugs.
\end{abstract}

\section{KEYWORDS}

Analytical methods;

besifloxacin;

fluoroquinolones; green analytical chemistry; quality control

\section{Introduction}

Infectious conjunctivitis has a high impact on public health, accounting for more than a third of eye conditions reported by health services worldwide. It is a highly contagious disease with the ability to spread rapidly. For these reasons, infectious conjunctivitis has a high impact on the population and on health services. ${ }^{[1]}$ The antimicrobial agents used to treat this pathology are very important, since they allow the reduction of its infectious propagation, absence time at work or school, recurrence of infection and the risk of progression to potentially irreversible ocular damage. ${ }^{[1-3]}$ However, in recent years there is a tendency of bacterial resistance to the most commonly used antimicrobials for this purpose. ${ }^{[2]}$

In this context, besifloxacin stands out. It is a fluoroquinolone exclusively recommended for ophthalmic use, recently inserted in the Brazilian market, which presents high efficiency against the major bacteria that cause infectious conjunctivitis, such as Staphylococcus aureus, Staphylococcus epidermidis, Streptococcus pneumoniae, and Haemophilus influenzae. Reports of resistance to this fluoroquinolone are not frequent, so this drug is of great importance for clinical practice nowadays. ${ }^{[3]}$ Besifloxacin is marketed as its hydrochloride form by Bausch \& Lomb, under the trade name Besivance ${ }^{\mathrm{TM}}$, in the pharmaceutical form of $0.6 \%$ ophthalmic suspension.

Thus, the quality control of this drug is essential, since poor quality antimicrobial agents may contribute to the aggravation of the bacterial resistance current situation. Therefore, the quality of these products must be strictly controlled and analytical methods need to be developed, validated, and improved for this purpose. ${ }^{[4]}$ These methods should preferably be environmentally friendly, since guaranteeing the quality of products and processes without damaging the environment meets the globalized needs. ${ }^{[5,6]}$ The development of analytical methods capable of reducing or eliminating the use and/or generation of hazardous substances for the environment and operators is one of the most important areas of Research and Development in Green Chemistry, in a subarea called Green Analytical Chemistry $(\mathrm{GAC}) .^{[5,7-9]}$

In this review, a search of the pharmaceutical and clinical aspects of besifloxacin was carried out to inform and assist the clinical community about the rational and responsible use of this drug in order to prevent the emergence of resistant strains and adverse effects. At the same time, a review of the analytical methods present in literature for the analysis of this drug was carried out. A discussion with emphasis on the 12 principles of GAC, proposed by Galuszka and collaborators (2013), was performed. ${ }^{[6]}$ These principles were based on the concepts of Green Chemistry proposed by Paul Anastas (1999). ${ }^{[5]}$

For this, searches were conducted using the MEDLINE, Science Direct, and SciFinder databases, until August 2017, using the English language. The main terms used were: "besifloxacin" in combination with "conjunctivitis," "chemical structure," "mechanism of action," "resistance," "pharmacokinetics," "antimicrobial activity," "clinical use," "side effects," "analytical methods," "green analytical method," "chromatography," "U-HPLC," "spectrophotometry," "spectrometry," "agar diffusion," "microbiological method," among others.

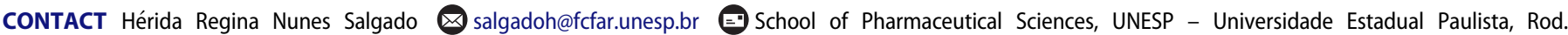
Araraquara-Jaú, km 1, ZIP 14800-903, Araraquara - SP - Brazil.

Color versions of one or more of the figures in the article can be found online at www.tandfonline.com/batc.

(c) 2018 Taylor \& Francis Group, LLC 


\section{Historical facts: Besifloxacin $\times$ conjunctivitis}

Conjunctivitis is an ocular pathology that affects people of all age groups and can be classified as infectious and noninfectious. Infectious conjunctivitis is caused mainly by bacteria, which account for $60 \%$ of the cases, but can also be caused by viruses (20\%) and to a lesser extent by fungi and parasites. ${ }^{[2,3,10]}$ More than a third of eye conditions reported by health services worldwide are related to infectious conjunctivitis. In addition, it is a highly contagious disease, with the ability to spread rapidly. For these reasons, infectious conjunctivitis has a high impact on the population and on health services. ${ }^{[1]}$

Usually, conjunctivitis is a self-limiting disease. Evidence indicates that patients not treated with antimicrobial agents have high rates of spontaneous remission and low risk of ocular sequelae, such as blindness and structural damage to the eyes. ${ }^{[3,11]}$ However, evidence also suggests that treatment with topical antimicrobial agents may shorten the time of disease, as well as reduce its contagious spread, absence time at work or school, recurrence of infection, and the risk of progression to potentially ocular damage, as reported in literature. ${ }^{[1-3]}$ Thus, the economic and personal benefits of proper treatment are evident.

Bacterial conjunctivitis in adults is mainly caused by Gram-positive bacteria Staphylococcus aureus, Staphylococcus epidermidis, and Streptococcus pneumoniae, as well as Gram-negative bacteria Haemophilus influenzae. While $S$. aureus is predominant in adults, $H$. influenzae predominates in children. ${ }^{[3]}$

Several classes of topical antimicrobials have been used in the treatment of this ocular pathology, such as aminoglycosides; combinations of polymyxin B with trimethoprim, bacitracin, and/or neomycin; macrolides and, more recently, fluoroquinolones, which are considered highly efficient and well tolerated by patients. However, in recent years, some microorganisms commonly associated with bacterial conjunctivitis have shown greater resistance to commonly used topical antimicrobial agents. Higher degree of resistance was found in Gram-positive bacteria, especially $S$. aureus. In this way, there is a growing need for new and more effective treatments to combat these bacteria. ${ }^{[2]}$

Fluoroquinolones are bactericidal antimicrobial agents, which act against Gram-positive and Gram-negative bacteria, many of them associated with conjunctivitis. ${ }^{[12]}$ This class of antimicrobials is widely used for the treatment of ocular infections due to their wide spectrum and low toxicity. ${ }^{[3]}$ In the last decades, several new fluoroquinolones have been developed, reflecting efforts to combat resistant bacteria. ${ }^{[2]}$

In the 1990s, the first fluoroquinolones for topical ophthalmic use were introduced in the North American market, including ciprofloxacin, ofloxacin, and norfloxacin, all belonging to second generation. Rapidly, ciprofloxacin and ofloxacin, due to their effectiveness, have reached the world market for the treatment and prophylaxis of ophthalmic infections. Norfloxacin was not as effective for this purpose. ${ }^{[13]}$

Later, three other fluoroquinolones were approved for ophthalmic use: levofloxacin, third generation; gatifloxacin and moxifloxacin, both of fourth generation. These three fluoroquinolones present higher activity against Gram-positive bacteria in relation to ciprofloxacin and ofloxacin. ${ }^{[13]}$ However, there are already reports in literature regarding bacterial resistance to all these antimicrobials, including from bacterial ophthalmic isolates. ${ }^{[2,3,12-18]}$

Although gatifloxacin and moxifloxacin present lower rates of resistance, these numbers are increasing, mainly because the same antimicrobials are also used for the treatment of systemic infections and for prophylaxis in surgical procedures, which are factors commonly associated with the occurrence of resistance. ${ }^{[3]}$ Thus, the importance of the development of antimicrobials for specialized use stands out. ${ }^{[2,3]}$

In this context, besifloxacin, the newest member of the fourth generation of fluoroquinolones, stands out. This antimicrobial was developed only for topical ophthalmic use, meeting current needs. In contrast to other fluoroquinolones, besifloxacin is not used for the treatment of systemic infections, making this antimicrobial unique in its class and presenting lower risk of developing resistance due to reduced systemic exposure. ${ }^{[3]}$

Besifloxacin, marketed as besifloxacin hydrochloride, was developed by the Japanese company SSP Co. Ltd., and named SS734. In 2000, the Japanese company licensed U.S. and European rights of this antimicrobial agent to InSite Vision, for ophthalmic use. Thus, InSite Vision developed an ophthalmic formulation (eye drops) (ISV-403) and conducted preliminary clinical trials before selling the product and all rights to Bausch \& Lomb in 2003. ${ }^{[19]}$

Besifloxacin has been approved in the United States by the Food and Drug Administration in May 2009 for the treatment of bacterial conjunctivitis in adults and children over one year of age. ${ }^{[3,20-22]}$ This fluoroquinolone started to be used in Brazil in 2011, when it was approved by the National Health Surveillance Agency, for the same purpose. ${ }^{[21]}$ This drug is marketed as besifloxacin hydrochloride (Chemical Abstract Service [CAS]: 405165-61-9) by the US pharmaceutical company Bausch \& Lomb, under the trade name Besivance ${ }^{\mathrm{TM}}$, in the pharmaceutical form of $0.6 \%$ ophthalmic suspension. This pharmaceutical form was developed with drug delivery technology known as DuraSite ${ }^{\mathrm{TM}}$ (InSite Vision, Inc., Alameda, USA), which makes the formulation more viscous than other suspensions and ophthalmic solutions, allowing the antimicrobial agent to remain for longer time in contact with the ocular surface. $^{[21,23]}$

\section{Pharmaceutical and clinical aspects}

\section{Chemical structure}

Besifloxacin (Figure 1) is chemically known as $\{7-[(3 R)-3$-aminohexahydro-1H-azepin-1-yl]-8-chloro-1-clyclopropyl-6-fluoro1,4-dihydro-4-oxo-3-quinolinecarboxylic acid\}. ${ }^{[24]}$ Its chemical formula is $\mathrm{C}_{19} \mathrm{H}_{21} \mathrm{ClFN}_{3} \mathrm{O}_{3}$ and the molecular weight is $430.40 \mathrm{~g} / \mathrm{mol}^{[22,25]}$

It is a synthetic chiral fluoroquinolone marketed in a pure enantiomeric form. ${ }^{[21]}$ Structurally, besifloxacin molecule has an important 1-N cyclopropyl group, which is responsible for the broad spectrum of activity of this fluoroquinolone against aerobic bacteria. This substituent also 


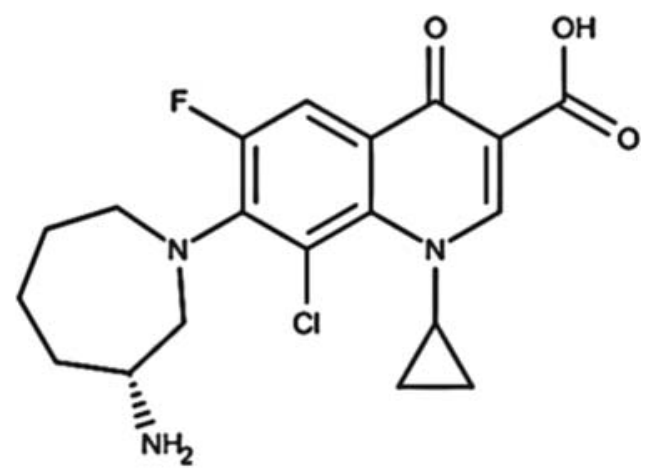

Figure 1. Chemical structure of besifloxacin.

appears in other fluoroquinolones, such as in ciprofloxacin, gatifloxacin, gemifloxacin, and moxifloxacin. ${ }^{[1,25]}$ The fluorine atom present at the 6-position of the molecule is an important pharmacophore. The chlorine atom, present in position 8 , is responsible for increasing the potency of the antimicrobial against bacterial enzymes DNA gyrase and topoisomerase IV, which increases its potency. ${ }^{[3,25]}$ Besifloxacin is not soluble in water and has pKas of 5.64 (strongest acidic, from hydroxyl) and 9.67 (strongest basic, from primary amine). ${ }^{[26,27]}$

\section{Synthesis route}

The first step in the synthesis of besifloxacin hydrochloride (Figure 2) is the condensation of the ethyl 3-(3-chloro-2,4,5-trifluorophenyl)-3-oxopropanoate compound (I) with triethyl orthoformate, generating a mixture of vinyl esters (II). Thereafter, there is a substitution with cyclopropanamine, which converts the compound II to vinyl amide (III), as a mixture of cis and trans-isomers, which was treated at elevated temperature to obtain structure IV. The trans-isomer isomerized to the cisisomer, which generates an intramolecular nucleophilic aromatic substitution with concomitant saponification to generate the quinolonic acid (IV). The quinolone (IV) is then subjected to another nucleophilic substitution involving iminoazepine and the displacement reaction proceeded regioselectively to provide the atomic structure of besifloxacin $(\mathrm{V})$. The acidic methanolysis of compound VI at elevated temperature resulted in besifloxacin hydrochloride (VI). ${ }^{[19]}$

\section{Mechanism of action and resistance}

Regarding the mechanism of action, as well as other fluoroquinolones, besifloxacin binds to bacterial enzymes DNA gyrase and topoisomerase IV, which are essential for DNA replication in bacteria. ${ }^{[1,28,29]}$ Thus, inhibition of these enzymes interferes with transcription, replication, and separation of bacterial chromosomal DNA during cell division. ${ }^{[20]}$ Fluoroquinolones have bactericidal action. ${ }^{[30,31]}$

Mechanisms of resistance to fluoroquinolones generally involve point mutations in the genes encoding the subunits of the bacterial enzymes DNA gyrase and topoisomerase IV, as well as changes in bacterial membrane efflux pumps. However, in the case of resistance, besifloxacin has some theoretical advantages over other fluoroquinolones. One of these advantages is the fact that it has high affinity for the two enzymes mentioned, unlike other fluoroquinolones, which have affinity for only one of them, which contributes to the occurrence of resistance. ${ }^{[1,28]}$ Thus, for a bacterium to become resistant to besifloxacin, it is necessary to develop spontaneous mutations in the genes that encode the subunits of these two enzymes, which is a less likely event to occur. ${ }^{[3]}$ In addition, besifloxacin is only available for topical ophthalmic use, which limits its systemic exposure and, consequently, reduces the development of resistance. $^{[20]}$

\section{Dosing and pharmacokinetics}

The recommended dosage for the treatment of bacterial conjunctivitis with Besivance ${ }^{\mathrm{TM}}$ is one drop in the affected eye three times a day (every 8 hours) for 5 days and may be extended to 7 days depending on the medical criteria. ${ }^{[22]}$ Some studies confirm the efficacy of this therapeutic regimen for the treatment of conjunctivitis. ${ }^{[32-34]}$ Other fluoroquinolones, such as ciprofloxacin, gatifloxacin, levofloxacin, and oxofloxacin, require more applications per day, being 1 to 2 drops every 2 hours in the first 2 days and then 1 to 2 drops, for at least 4 times a day, for another 5 days. Only moxifloxacin presents dosage equivalent to besifloxacin. ${ }^{[2]}$ Thus, the besifloxacin dosing regimen is advantageous over the other fluoroquinolones used for the treatment of conjunctivitis, which contributes to the patient adherence to treatment and, consequently, to therapeutic success. $^{[3]}$

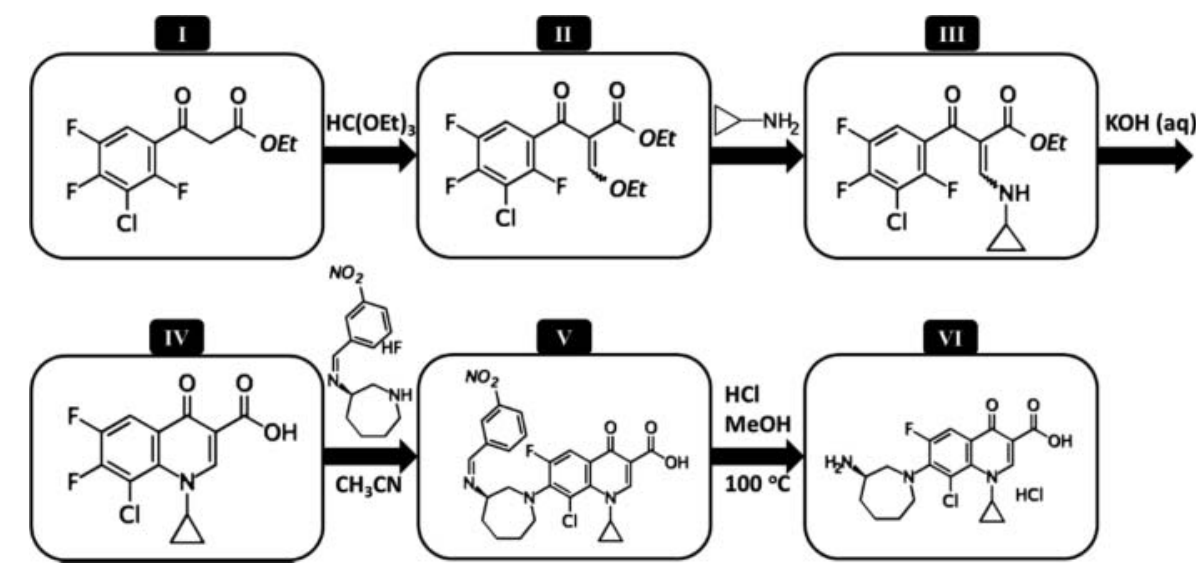

Figure 2. Synthesis route of besifloxacin hydrochloride. Source: adapted from. ${ }^{[19]}$ 
Pharmacokinetic study carried out by Ward, Lepage, and Driot (2007) showed that after a single application of Besivance $^{\mathrm{TM}}$ in rabbits, very low levels of antimicrobial were found in the plasma $(<10 \mathrm{ng} / \mathrm{mL})$, which demonstrates minimal systemic exposure of besifloxacin in ophthalmic suspension. In addition, the binding of besifloxacin to plasma proteins was low (38.5-44.0\%). The authors also observed that DuraSite $^{\mathrm{TM}}$ release technology used for the formulation of besifloxacin $0.6 \%$ ophthalmic suspension, makes the ocular mean residence time (MRT) of this antimicrobial be long-lasting. In tears, conjunctiva, aqueous humor, and rabbit plasma, the observed MRT values were 923, 458, 422, and 689 minutes, respectively. Although the MRT of besifloxacin in plasma was of long duration, the drug concentration was generally very low $(<0.01 \mu \mathrm{g} / \mathrm{mL}){ }^{[35]}$

Another study, conducted with adults suspected of bacterial conjunctivitis who received Besivance ${ }^{\mathrm{TM}}$ bilaterally three times a day (total of 16 doses), also demonstrated the minimal systemic exposure of the antimicrobial, since after the first and last dose, the maximum plasma concentration $\left(\mathrm{C}_{\max }\right)$ in each patient was less than $1.3 \mathrm{ng} / \mathrm{mL}$. The mean $\mathrm{C}_{\max }$ of besifloxacin was $0.37 \mathrm{ng} / \mathrm{mL}$ on first day and $0.43 \mathrm{ng} / \mathrm{mL}$ on sixth day. The elimination half-life of besifloxacin in plasma after multiple dosing was estimated at 7 hours. $^{[22]}$

Proksch and coworkers (2009) studied the pharmacokinetics of besifloxacin in 64 healthy volunteers. The authors observed that the maximum concentration of besifloxacin in the tear fluid of the volunteers was $610 \mu \mathrm{g} / \mathrm{g}$ after 10 minutes of topical administration. They also noted that a concentration of $10 \mu \mathrm{g} /$ $\mathrm{g}$ was maintained in the tear after 12 hours, and of $1.60 \mu \mathrm{g} / \mathrm{g}$ after 24 hours. These concentrations are considerably above the minimum inhibitory concentration required to eliminate $90 \%$ $\left(\mathrm{MIC}_{90}\right)$ of most of the bacteria responsible for conjunctivitis, such as $S$. pneumoniae, $S$. aureus, $S$. epidermidis, and $H$. influenzae. The elimination half-life of besifloxacin in human tears was estimated at 3.4 hours. ${ }^{[36]}$

\section{Microbiological spectrum and clinical use}

Besifloxacin hydrochloride, in the pharmaceutical dosage form of $0.6 \%$ ophthalmic suspension, is indicated for the treatment of bacterial conjunctivitis caused by the following bacteria: Aerococcus viridans, Corynebacterium CDC Group G, Corynebacterium pseudodiphtheriticum, Corynebacterium striatum, Haemophilus influenzae, Moraxella catarrhalis, Moraxella lacunate, Pseudomonas aeruginosa, Staphylococcus aureus, Staphylococcus epidermidis, Staphylococcus hominis, Staphylococcus lugdunensis, Staphylococcus warneri, Streptococcus mitis group, Streptococcus oralis, Streptococcus pneumoniae, and Streptococcus salivarius. ${ }^{[22]}$

Study conducted by Haas et al. (2009) showed that besifloxacin presents lower minimum bactericidal concentration than moxifloxacin, gatifloxacin, ciprofloxacin, azithromycin, and tobramycin for S. aureus, S. epidermidis, and S. pneumoniae, proving that it is the most potent antimicrobial agent used against these bacteria. In addition, besifloxacin showed greater efficiency against Gram-positive and Gram-negative bacteria resistant to other fluoroquinolones. ${ }^{[37]}$
Haas et al. (2010), later, evaluated the bactericidal activity of besifloxacin and other antimicrobial agents (oxacillin, tobramycin, azithromycin, ciprofloxacin, moxifloxacin, and gatifloxacin) against the following common bacterial conjunctivitis pathogens: S. aureus, S. epideridis, S. pneumoniae, and H. influenzae. Results have indicated that besifloxacin unlike the other tested fluoroquinolones, besifloxacin showed high potency and bactericidal activity even against strains that contained multiple mutations in genes encoding DNA gyrase and topoisomerase IV. ${ }^{[38]}$

Brown-Elliott et al. (2012) evaluated the susceptibility of atypical or nontuberculous mycobacteria associated with eye infections to 10 antimicrobials, including besifloxacin. The main isolates were Mycobacterium abscessus, Mycobacterium chelonae, and Mycobacterium fortuitum. The most active antimicrobial agents against $M$. abscessus were amikacin and clarithromycin/azithromycin. Quinolones (including besifloxacin, but mainly gatifloxacin and ciprofloxacin), clarithromycin/azithromycin, amikacin and tobramycin were more active against M. chelonae. Quinolones have also been shown to be more potent against $M$. fortuitum. ${ }^{[39]}$

In addition to the antimicrobial activity, study conducted by Zhang and Ward (2008) showed that besifloxacin also acts as an anti-inflammatory agent in monocytes in vitro, which may improve its efficacy in ocular infections with an inflammatory component. $^{[24]}$

\section{Side effects}

The systemic toxicity caused by besifloxacin is low, as its systemic exposure is negligible. ${ }^{[36]}$ This antimicrobial is well tolerated by patients, with the occurrence of few adverse effects, which are mild in severity and transient in nature. The most common adverse event is conjunctival redness, but there are also reports of blurred vision, ocular pain, eye irritation, ocular pruritus, and headache. ${ }^{[22]}$

Comstock and coworkers (2010) evaluated the safety and tolerability of besifloxacin ophthalmic suspension $0.6 \%$ in the treatment of bacterial conjunctivitis across clinical and phase I safety studies, in 1350 patients. The authors confirmed the drug systemic exposure was negligible. No changes in corneal endothelial cell density were observed. Blurred vision, eye pain, eye irritation, nonspecific conjunctivitis and eye pruritus were the most reported adverse events, however, in a small percentage $(<2.1 \%)$ and mild in severity. Regarding non-ocular adverse events, the most frequently reported was headache $(1.8 \%)$. In this way, the study concluded that besifloxacin ophthalmic suspension $0.6 \%$ is well tolerated and has satisfactory safety profile. ${ }^{[40]}$

Silverstein and coworkers (2011) evaluated the efficacy and tolerability of besifloxacin ophthalmic suspension $0.6 \%$ when administrated twice daily for 3 days, in adults and children with bacterial conjunctivitis. Bacterial conjunctivitis, conjunctivitis, and allergic conjunctivitis were the most related adverse events, in a low percentage $(<1.9 \%)$ and of mild or moderate severity. The authors concluded this dosage scheme was effective and well tolerated by patients. ${ }^{[34]}$

Malhotra and coworkers (2012) investigated the safety and tolerability of besifloxacin ophthalmic suspension $0.6 \%$ 
compared with moxifloxacin ophthalmic solution $0.5 \%$, when used prophylactically to prevent postoperative endophthalmitis following sutureless cataract surgery. The results obtained with both medicines were similar, and the authors concluded besifloxacin was well tolerated, since no adverse events were reported. ${ }^{[41]}$

\section{Analytical methods and stability studies: A green approach}

Monitoring the quality of pharmaceuticals is an extremely important practice for the health of the population. Any health service can be severely compromised if the drugs available to users do not meet acceptable standards of quality, safety, and efficacy. This importance becomes even more evident when we consider the quality of antimicrobials used in clinical practice. According to the Global Report on Surveillance of Antimicrobial Resistance, published by WHO in 2014, antimicrobial resistance is no longer a predictor for the future, as is happening right now, all over the world, and endangering the ability of health systems to treat community and hospital-acquired common infections. ${ }^{[42]}$ In this context, low quality antimicrobials may contribute to the aggravation of this situation, and the quality of these products must be strictly controlled. Thus, it is essential that the Quality Control of the pharmaceutical industries rely on effective and fully reliable analytical methods to monitor the quality of their pharmaceutical products. ${ }^{[4]}$

Alongside the importance of developing reliable analytical methods for analysis of drugs, nowadays there is also a great concern for the impact that these methods can have on the environment. The demanding public opinion and the trend toward sustainable consumption gave rise to the first concepts of Green Chemistry in the 1990s. The main concept of Green Chemistry is the use of chemical skills and knowledge to reduce or eliminate the use or generation of hazardous substances during the planning, manufacture, and application of chemicals in order to minimize threats to the health of operators and on the environment. ${ }^{[5]}$ One of the most active areas of Research and Development in Green Chemistry is the development of analytical methodologies. New methods and techniques that are capable of reducing and eliminating the use and generation of hazardous substances at all stages of chemical analysis are the main targets of the so-called GAC. ${ }^{[5,7-9]}$ GAC concepts also extend to the analysis of pharmaceuticals.

Anastas (1998) proposed 12 principles for Green Chemistry, which were adapted by Galuszka, Migaszewski, and Namiénski (2013), to better satisfy the GAC. ${ }^{[6,43]}$ The 12 principles of GAC are shown in Figure 3.

In literature, there are few published works that present the development of analytical methods for the analysis of besifloxacin, and all of them are presented in Table 1. Figure 4 (a) shows a graphical representation of these works.

Most of published works describe high performance liquid chromatography (HPLC) for the analysis of besifloxacin in different matrices, such as human lacrimal fluids, ${ }^{[44]} \mathrm{rab}-$ bit plasma and ocular tissues, ${ }^{[45]}$ ophthalmic suspension, ${ }^{[21,46,47]}$ raw material, ${ }^{[47]}$ cornea and aqueous humor, ${ }^{[48]}$ and a mixture of enantiomers ( $R$-besifloxacin, used in the antimicrobial formulations, and $S$-besifloxacin, its main impurity). ${ }^{[49]}$

HPLC is one of the most important members of a family of separation techniques. To perform this technique, small columns filled with specially prepared materials and a mobile phase are required. The mobile phase is eluted under high pressure with the aid of very sophisticated equipment, which can be completely automated. This method is notable for presenting some special properties, such as the ability to perform separations and quantitative analyzes of a large number of compounds present in a sample in a few minutes, with high resolution, efficiency, and sensitivity. ${ }^{[50]}$ In addition, it allows repetitive and reproductive analyzes with the same column and allows the use of a wide variety of mobile and stationary phases, which contributes to its prominent position among instrumental analysis methods. ${ }^{[51]}$

However, in all described HPLC methods (Table 1), solvents potentially toxic to the environment and health of operators (acetonitrile, methanol, $\mathrm{n}$-heptane, and ethylenediamine) were used in the composition of the mobile phases (Figure $4[\mathrm{~b}]$ ). ${ }^{[2]}$ This fact is not in accordance with the 11th and 12th principles of the GAC, mainly. In a search in literature, it is also possible to find many works describing chromatographic methods for

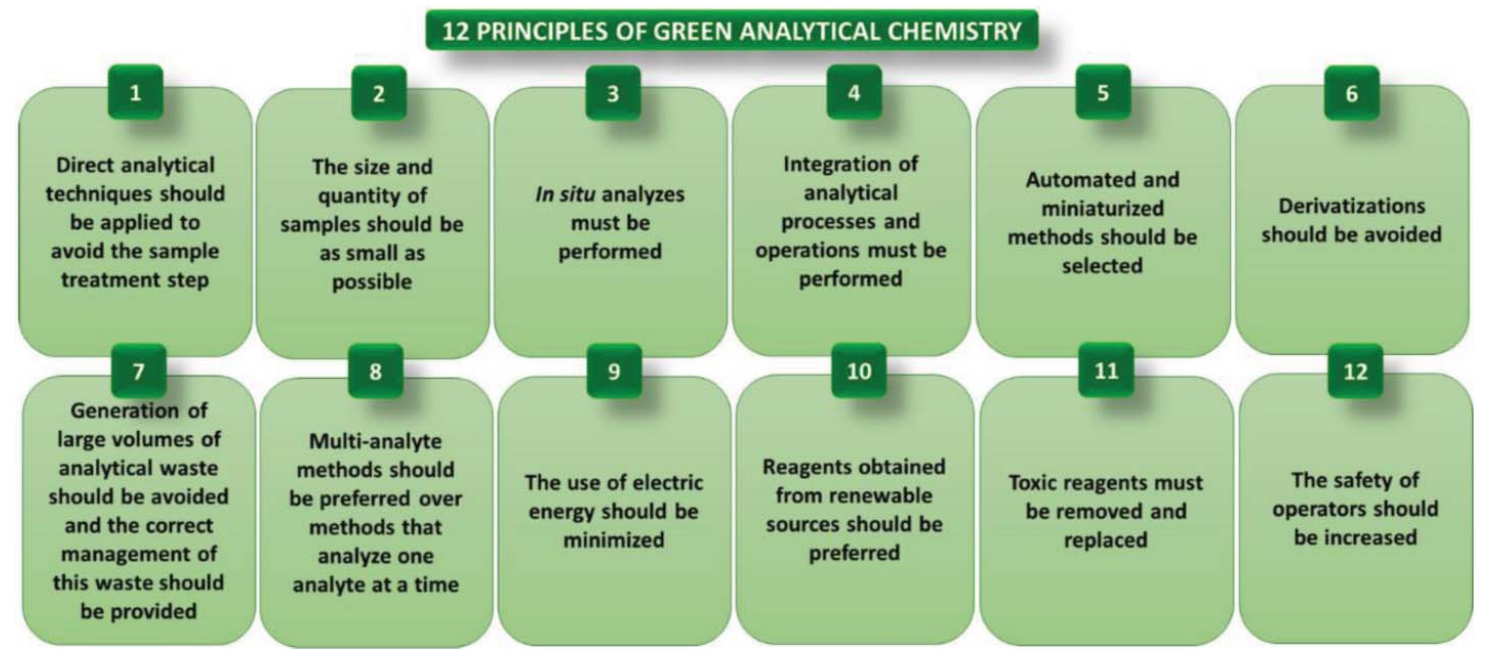

Figure 3. 12 principles of Green Analytical Chemistry proposed by Galuszka, Migaszewski, and Namiénski (2013). ${ }^{[6]}$ 
CRITICAL REVIEWS IN ANALYTICAL CHEMISTRY

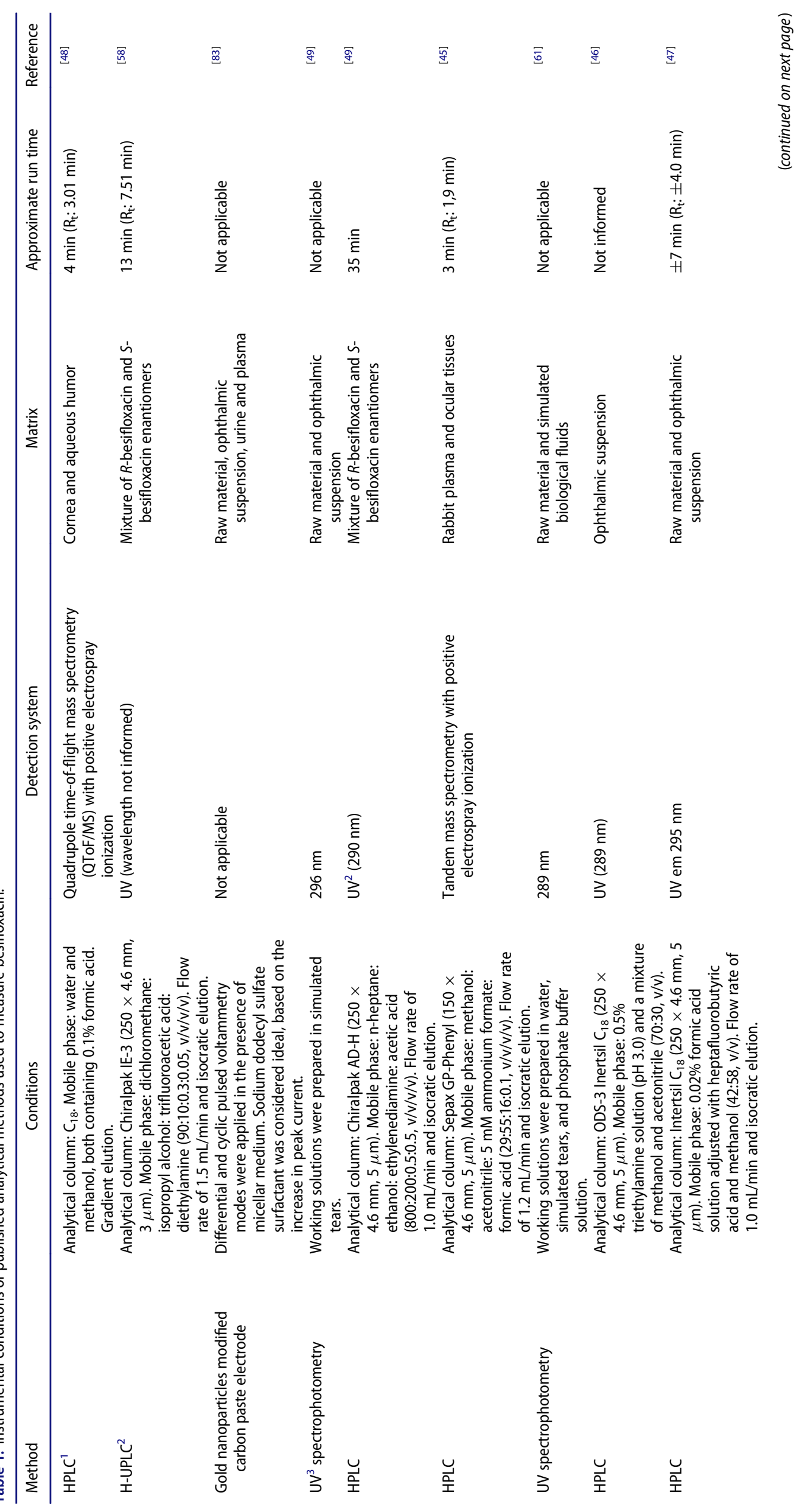




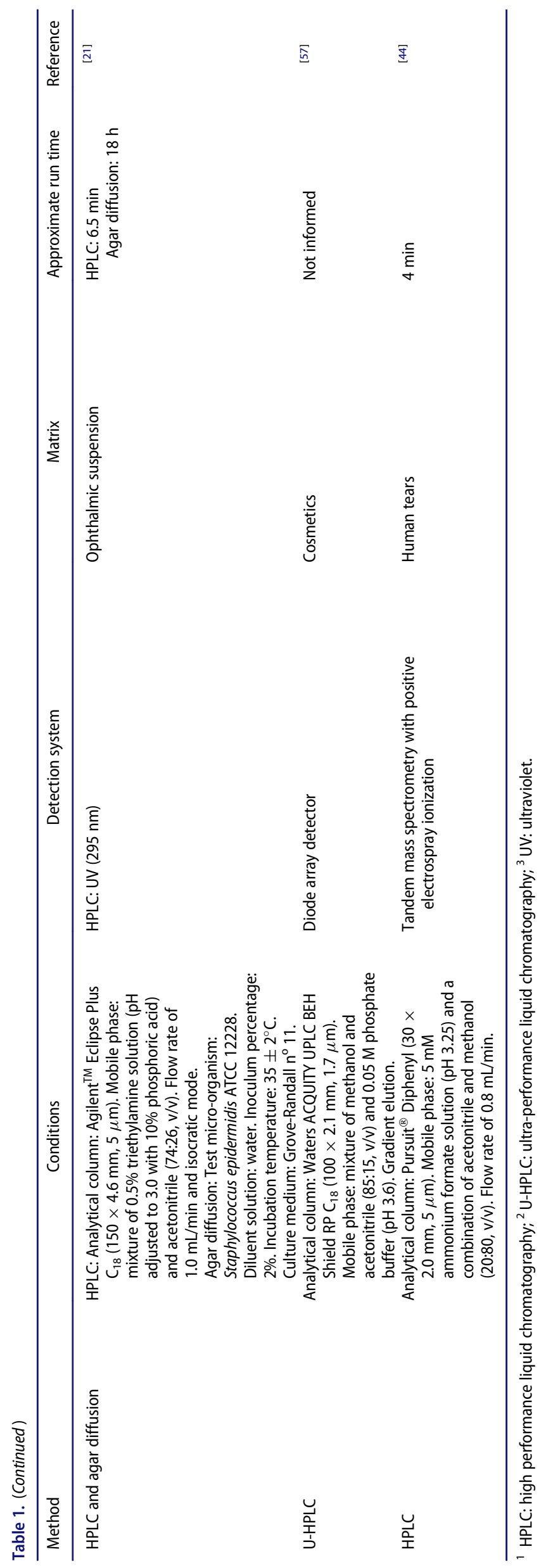




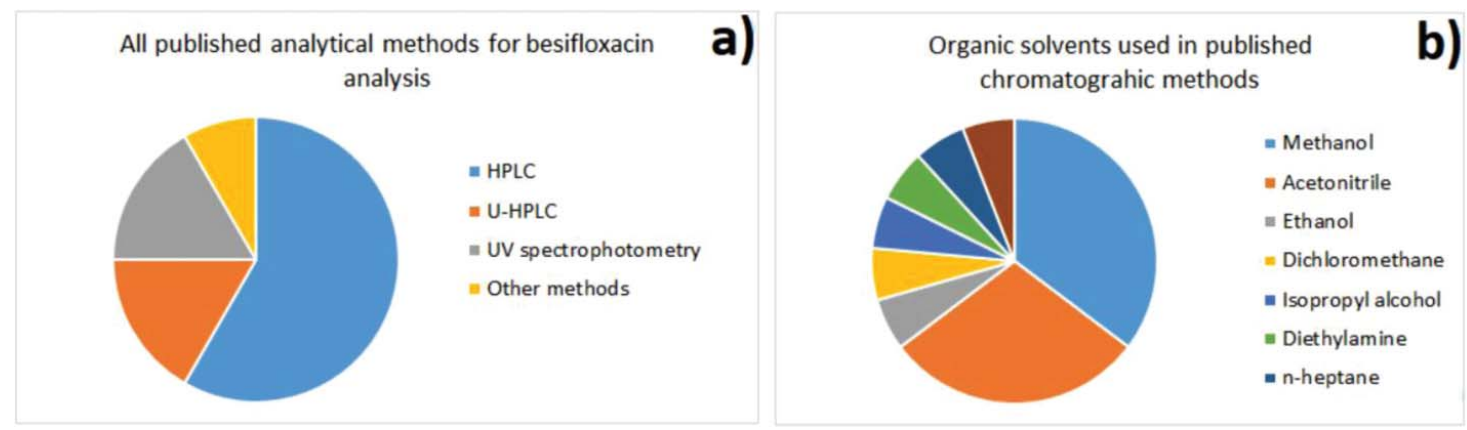

Figure 4. (a) Graphical representation of published analytical methods for the analysis of besifloxacin in different matrices. (b) Graphical representation of organic solvents used in published chromatographic methods for the analysis of besifloxacin in different matrices (by HPLC and U-HPLC).

other fluoroquinolones, such as orbifloxacin, ${ }^{[53]}$ norfloxacin, ${ }^{[54]}$ and sparfloxacin. ${ }^{[5,56]}$

Ultra-efficient liquid chromatography (U-HPLC), in turn, was used to analyze besifloxacin and other quinolones in cosmetics ${ }^{[57]}$ and in a mixture of $R$-besifloxacin and $S$-besifloxacin enantiomers. ${ }^{[58]}$ U-HPLC technique is more modern than HPLC and has numerous advantages over it. The main advantage is the reduced analysis time, since the $\mathrm{U}$ HPLC analyzes are considerably faster than in HPLC, which generates solvent and electric energy savings and is, therefore, environmentally favorable. This technique also presents better sensitivity and resolution. Regarding the separation mechanisms, they are the same as in HPLC; however, the analytical columns used in this case are usually smaller, packed with smaller particle sizes. ${ }^{[59]}$

In all described U-HPLC methods for besifloxacin analysis (Table 1), the authors also opted for the use of potentially toxic solvents (methanol, acetonitrile, dichloromethane, and isopropyl alcohol) (Figure 4b), as well as buffer solution, which can cause clogging in the chromatographic system, reducing its useful life. ${ }^{[60]}$

Different detectors were used for the methods of HPLC and U-HPLC, such as UV and/or DAD, ${ }^{[21,46,47,49,57,58]}$ and mass spectrometer. ${ }^{[4,45,48]}$

Two studies propose the development and validation of spectrophotometric methods in UV region for the analysis of besifloxacin. ${ }^{[49,61]}$ One of these studies aimed to quantify the drug in raw material and ophthalmic suspension ${ }^{[49]}$ and the other in raw material and simulated biological fluids. ${ }^{[61]}$ Spectrophotometry in the UV region is an instrumental method widely used for the quantification of drugs, since it is considered simple, fast, economical, and reproducible. ${ }^{[62-65]}$ However, it is a non-selective method and is not suitable for the detection of degradation products and impurities. ${ }^{[66]}$ Spectrophotometric methods are also found in literature for other fluoroquinolones, such as ciprofloxacin, ${ }^{[67]}$ norfloxacin, ${ }^{[68,69]}$ orbifloxacin, ${ }^{[70]}$ lomefloxacin, ${ }^{[71]}$ gatifloxacin, ${ }^{[72]}$ and sparfloxacin. ${ }^{[73,74]}$

Costa et al. (2014) developed and validated a microbiological agar diffusion method for the potency analysis of besifloxacin in ophthalmic suspension. ${ }^{[21]}$ However, this method requires 24 hours for the analysis of results, and this time is considered high for routine analyzes of the quality control in a pharmaceutical industry. Long periods of analysis also result in a greater expenditure of electrical energy, going against the 9th principle of the GAC. Microbiological methods are also found for other fluoroquinolones, for example orbifloxacin, ${ }^{[75]}$ ciprofloxacin, ${ }^{[76]}$ norfloxacin, ${ }^{[77]}$ and sparfloxacin. ${ }^{[78-80]}$

Microbiological methods play an essential role in the manufacturing and quality control processes of antimicrobials as they provide information on the biological activity of these drugs that the physicochemical methods are not able to provide. Often the part of the molecule essential for antimicrobial activity may not be the same detected in the physicochemical method, generating false conclusions about the quality of the drug. ${ }^{[81,82]}$

Attia et al. (2016) developed and validated a complex electrochemical method using gold nanoparticles modified carbon paste electrode in micellar medium for the analysis of besifloxacin in raw material, ophthalmic suspension, urine, and plasma. Gold is a nonrenewable resource, so this method is opposed to the 10th principle of GAC. ${ }^{[83]}$

Traditional volumetric methods are also described for fluoroquinolones such as non-aqueous titration using perchloric acid. $^{[84,85]}$

Costa et al. (2014) were also the only authors to describe a stability study for besifloxacin. The objective of this study was to demonstrate the selectivity of a chromatographic method previously validated by them. Besifloxacin was subjected to forced conditions of degradation in acidic, alkaline, thermal, oxidative, and photolytic media. Besifloxacin sample was maintained under these conditions for only one hour (with the exception of thermal condition, in which the sample remained for 24 hours). In thermal and basic conditions, besifloxacin remained stable in this period. In the photolytic, acid and oxidative conditions, there were signs of drug degradation, but without the detection of new peaks in the chromatograms. The drug demonstrated greater instability under photolytic conditions. $^{[21]}$

The question of how much the drug should be degraded raises controversy and is not very well established. In general, for the development of stability-indicating methods, the acceptable is a degradation in the range of 5 to $20 \%$. A higher degradation can lead the formation of secondary degradation products, which are not commonly found under normal shelf conditions, therefore not being considered products of interest. $^{[86,87]}$

Thus, there is a need for further stability studies regarding besifloxacin, since in the only study found in literature, the authors submitted the drug to stressful conditions for a very short period, failing to achieve degradation in the range of 5 to 
$20 \%$, as recommended. ${ }^{[21]}$ At the same time, accelerated and long-term stability studies were not found in literature.

It is possible to observe that there is a gap in literature regarding practical and environmentally friendly analytical methods for the analysis of besifloxacin, as well as more detailed stability studies.

\section{Conclusions}

Conjunctivitis, which accounts for more than a third of eye problems reported in health services worldwide, although it is a self-limiting disease, needs to be treated with effective antimicrobials in order to reduce the time of disease and its contagious spread, absence at work and school, and the risk of permanent eye damage.

According to the literature review, besifloxacin is a very important drug for the treatment of infectious conjunctivitis, since it presents less occurrence of bacterial resistance than other drugs used for the same purpose and, at the same time, presents great efficacy and tolerability. The low rate of resistance to this antimicrobial is mainly due to its exclusively topical ophthalmic use.

Considering the importance of besifloxacin for clinical practice, its quality should be strictly controlled in order to reduce the risk of bacterial resistance and, at the same time, ensure its therapeutic efficacy and patient safety. For this, reliable analytical methods must be developed for this purpose. These methods should preferably be green in order not to cause harm to the environment and the health of operators, in accordance with the principles of Green Chemistry and GAC. The literature review in this regard showed that most of the described methods do not meet these requirements, since they make the use of potentially toxic solvents. This fact shows the urgent need for the development of new methods, which comply with the principles of GAC, in order to meet global needs. The need for further stability studies of this drug has also been noted.

\section{Acknowledgments}

The authors acknowledge CNPq (437489/2016-7), PADC-FCF, and Bausch \& Lomb.

\section{Funding}

This work was supported by Conselho Nacional de Desenvolvimento Científico e Tecnológico (304824/2013-5).

\section{ORCID}

Hérida Regina Nunes Salgado (iD) http://orcid.org/0000-0002-0385-340X

\section{References}

[1] Saher, O.; Ghorab, D. M.; Mursi, N. M. Levofloxacin Hemihydrate Ocular Semi-Sponges for Topical Treatment of Bacterial Conjunctivitis: Formulation and In-Vitro/In-Vivo Characterization. J. Drug Deliv. Sci. Technol. 2016, 31, 22-34. doi:10.1016/j.jddst.2015.11.004.

[2] Karpecki, P.; Paterno, M. R.; Comstock, T. L. Limitations of Current Antibiotics for the Treatment of Bacterial Conjunctivitis. Optom. Vis. Sci. 2010, 87, 908-919. doi:10.1097/OPX.0b013e3181f6fbb3.
[3] Khimdas, S.; Visscher, K. L.; Hutnik, C. M. L. Ophthalmology and Eye Diseases Besifloxacin Ophthalmic Suspension: Emerging Evidence of its Therapeutic Value in Bacterial Conjunctivitis. Ophthalmol. Eye Dis. 2011, 3, 7-12. doi:10.4137/OED.S4102.

[4] La Roca, M. F.; Sobrinho, J. L. S.; Nunes, L. C. C.; Neto, P. J. R. Desenvolvimento e Validação De método analítico: Passo Importante na produção De Medicamentos. Rev. Bras. Farmácia 2007, 88, 177-180.

[5] Anastas, P. T. Green Chemistry and the Role of Analytical Methodology Development. Crit. Rev. Anal. Chem. 1999, 29, 167-175. doi:10.1080/10408349891199356.

[6] Gałuszka, A.; Migaszewski, Z.; Namiesnik, J. The 12 Principles of Green Analytical Chemistry and the Significance Mnemonic of Green Analytical Practices. Trends Anal. Chem. 2013, 50, 78-84. doi:10.1016/j.trac.2013.04.010.

[7] Sanseverino, A. M. Síntese orgânica limpa. Quim. Nova 2010, 23, 102-107. doi:10.1590/S0100-40422000000100018.

[8] Nolasco, F. R.; Tavares, G. A.; Bendassolli, J. A. Establishment of Laboratory Waste Management Programs in Universities: Critical Review and Recommendations. Eng. Sanitária e Ambient. 2006, 11, 118-124. doi:10.1590/s1413-41522006000200004.

[9] De La Guardia, M.; Armenta, S. Green Analytical Methods. Anal. Bioanal. Chem. 2012, 404, 625-626. doi:10.1007/s00216-012-6208-z.

[10] Mejía-López, H.; Pantoja-Meléndez, C. A.; Climent-Flores, A.; Lucio, V. M. B. Epidemiological Aspects of Infectious Conjunctivitis. In Conjunctivitis - A complex multifaceted disord; Pelikan, Z., Ed; InTech: Rijeka, Croácia, 2011; pp. 1-18.

[11] Lal, S. C.; Amit, S.; Sokindra, K.; Majumdar, D. K. Besifloxacinthe Fourth Generation Fluoroquinolone: A Review. J. Drug Deliv. Ther. 2014, 4, 39-44.

[12] Redgrave, L. S.; Sutton, S. B.; Webber, M. A.; Piddock, L. J. V. Fluoroquinolone Resistance: Mechanisms, Impact on Bacteria, and Role in Evolutionary Success. Trends Microbiol., 2014, 22, 438-445. doi:10.1016/j.tim.2014.04.007.

[13] Hwang, D. G. Fluoroquinolone Resistance in Ophthalmology and the Potential Role for Newer Ophthalmic Fluoroquinolones. Surv. Ophthalmol. 2004, 49, S79-S83. doi:10.1016/j.survophthal.2004.01.004.

[14] Asbell, P. A.; Colby, K. A.; Deng, S.; McDonnell, P.; Meisler, D. M.; Raizman, M. B.; Sheppard, J. D. Jr.; Sahm, D. F. Ocular TRUST: Nationwide Antimicrobial Susceptibility Patterns in Ocular Isolates. Am. J. Ophthalmol. 2008, 145, 951-958. doi:10.1016/j. ajo.2008.01.025

[15] Betanzos-Cambrera, G.; Juárez-Verdayes, M. A.; González-González, G.; Cancino-Díaz, M. E.; Cancino-Díaz, J. C. Gatifloxacin, Moxifloxacin, and Balofloxacin Resistance Due to Mutations in the gyrA and parC Genes Of Staphylococcus Epidermidis Strains Isolated From Patients With Endophthalmitis, Corneal Ulcers And Conjunctivitis. Ophthalmic Res., 2009, 42, 43-48. doi:10.1159/000219684.

[16] Iffat, W.; Shoaib, M. H.; Muhammad, I. N.; Rehana, ; Tasleem, S.; Gauhar, S. Antimicrobial Susceptibility Testing of Newer Quinolones Against Gram Positive And Gram Negative Clinical Isolates. Pak. J. Pharm. Sci. 2010, 23, 245-249.

[17] Kresken, M.; Koerber-Irrgang, W.; Behrens-Baumann, B. Antimicrobial Resistance Among Ocular Isolates Recovered from Patients with Superficial Eye Infections in Germany. Chemother. J. 2012, 21, 8-24.

[18] Miller, D.; Flynn, P. M.; Scott, I. U.; Alfonso, E. C.; Flynn, H. W. In Vitro fluoroquinolone resistance in Staphylococcal Endophthalmitis Isolates. Arch. Ophthalmol. 2006, 124, 479-483. doi:10.1001/ archopht.124.4.479.

[19] Liu, K.K.- C.; Sakya, S. M.; O’Donnell, C. J.; Flick, A. C.; Li, J. Synthetic Approaches to the 2009 New Drugs. Bioorg. Med. Chem. 2011, 19, 1136-1154. doi:10.1016/j.bmc.2010.12.038.

[20] Chang, M. H.; Fung, H. B. Besifloxacin: A Topical Fluoroquinolone for the Treatment of Bacterial Conjunctivitis. Clin. Ther. 2010, 32, 454-471. doi:10.1016/j.clinthera.2010.03.013.

[21] Costa, M. C. N.; Barden, A. T.; Andrade, J. M. M.; Oppe, T. P.; Schapoval, E. E. S. Quantitative Evaluation of Besifloxacin Ophthalmic Suspension by HPLC, Application to Bioassay Method and Cytotoxicity Studies. Talanta 2014, 119, 367-374. doi:10.1016/j. talanta.2013.10.051. 
[22] Besivance: Prescribing Information. http://www.besivancesamplere quest.com/ (accessed Sept 17, 2017).

[23] Carter, N. J.; Scott, L. J. Besifloxacin Ophthalmic Suspension 0.6\%. Adis Drug Profile 2010, 70, 83-97.

[24] Zhang, J.- Z.; Ward, K. W. Besifloxacin, a Novel Fluoroquinolone Antimicrobial Agent, Exhibits Potent Inhibition of Pro-Inflammatory Cytokines In Human THP-1 Monocytes. J. Antimicrob. Chemoterapy 2008, 61, 111-116. doi:10.1093/jac/dkm398.

[25] Brito, M. A.; Cordeiro, B. C. Besifloxacin, a Fluoroquinolone Antibiotic. Rev. Eletrônica Farmácia 2013, X, 69-80.

[26] Besifloxacin: Chemical Characteristics. https://www.drugbank.ca/ drugs/DB06771 (accessed July 23, 2017).

[27] Besifloxacin: Chemical Characteristics. https://chemicalize.com/\#/cal culation (accessed August 5, 2017).

[28] Cambau, E.; Matrat, S.; Pan, X.- S.; Bettoni, R. R. D.; Corbel, C.; Aubry, A.; Lascols, C.; Driot, J.- Y.; Fisher, L. M. Target Specificity of the New Fluoroquinolone Besifloxacin in Streptococcus Pneumoniae, Staphylococcus Aureus and Escherichia Coli. J. Antimicrob. Chemother. 2009, 63, 443-450. doi:10.1093/jac/dkn528.

[29] Mah, F. S.; Sanfilippo, C. M. Besifloxacin: Efficacy and Safety in Treatment and Prevention of Ocular Bacterial Infections. Ophthalmol. Ther. 2016, 5, 1-20. doi:10.1007/s40123-016-0046-6.

[30] Blondeau, J. M. Fluoroquinolones: Mechanism of Action, Classification, and Development of Resistance. Surv. Ophthalmol. 2004, 49, S73-S78. doi:10.1016/j.survophthal.2004.01.005.

[31] Mah, F. S. Fourth-Generation Fluoroquinolones: New Topical Agents in the War on Ocular Bacterial Infections. Curr. Opin. Ophthalmol. 2004, 15, 316-320.

[32] Karpecki, P.; Depaolis, M.; Hunter, J. A.; White, E. M.; Rigel, L.; Brunner, L. S.; Usner, D. W.; Paterno, M. R.; Comstock, T. L. Besifloxacin Ophthalmic Suspension 0.6\% in Patients with Bacterial Conjunctivitis: A Multicenter, Prospective, Efficacy and Safety Study. Clin. Ther. 2009, 31, 514-526. doi:10.1016/S0149-2918(09)00085-X.

[33] McDonald, M. B.; Protzko, E. E.; Brunner, L. S.; Morris, T. W.; Haas, W.; Paterno, M. R.; Comstock, T. L.; Usner, D. W. Efficacy and Safety of Besifloxacin Ophthalmic Suspension 0.6\% Compared with Moxifloxacin Ophthalmic Solution 0.5\% for Treating Bacterial Conjunctivitis. Ophthalmology 2009, 116, 1615-1623. doi:10.1016/j. ophtha.2009.05.014.

[34] Silverstein, B. E.; Allaire, C.; Bateman, K. M.; Gearinger, L. S.; Morris, T. W.; Comstock, T. L. Efficacy and Tolerability of Besifloxacin Ophthalmic Suspension $0.6 \%$ Administered Twice Daily for 3 Days in the Treatment of Bacterial Conjunctivitis: A Multicenter, ParallelGroup Study in Adults and Children. Clin. Ther. 2011, 33, 13-26. doi:10.1016/j.clinthera.2010.12.004.

[35] Ward, K. W.; Lepage, J.- F.; Driot, J.- Y. Nonclinical Pharmacodynamics, Pharmacokinetics, and Safety of Bol-303224-A, a Novel Fluoroquinolone Antimicrobial Agent for Topical Ophthalmic Use. J. Ocul. Pharmacol. Ther. 2007, 23, 243-256. doi:10.1089/ jop.2006.0137.

[36] Proksch, J. W.; Granvil, C. P.; Siou-Mermet, R.; Comstock, T. L.; Paterno, M. R.; Ward, K. W. Ocular Pharmacokinetics of Besifloxacin Following Topical Administration to Rabbits, Monkeys, and Humans. J. Ocul. Pharmacol. Ther. 2009, 25, 335-344. doi:10.1089/ jop.2008.0116.

[37] Haas, W.; Pillar, C. M.; Zurenko, G. E.; Lee, J. C.; Brunner, L. S.; Morris, T. W. Besifloxacin, A Novel Fluoroquinolone, Has Broad-Spectrum in vitro activity against aerobic and anaerobic bacteria. Antimicrob. Agents Chemother. 2009, 53, 3552-3560. doi:10.1128/ AAC.00418-09.

[38] Haas, W.; Pillar, C. M.; Hesje, C. K.; Sanfilippo, C. M.; Morris, T. W. Bactericidal Activity Of Besifloxacin Against Staphylococci, Streptococcus Pneumoniae and Haemophilus Influenzae. J. Antimicrob. Chemother. 2010, 65, 1441-1447. doi:10.1093/jac/dkq127.

[39] Brown-Elliott B. A.; Mann, L. B.; Hail, D.; Whitney C.; Wallace, RJ, Jr. Antimicrobial Susceptibility of Nontuberculous Mycobacteria from Eye Infections, Cornea. 2012, 31, 900-906. doi:10.1097/ ICO.0b013e31823f8bb9.

[40] Comstock, T. L.; Paterno, M. R.; Decory, H. H.; Usner, D. W. Safety and Tolerability of Besifloxacin Ophthalmic Suspension $0.6 \%$ in the
Treatment of Bacterial Conjunctivitis: Data From Six Clinical and Phase I Safety Studies. Clin. Drug Investig. 2010, 30, 675-685. doi:10.2165/11536720-000000000-00000.

[41] Malhotra, R.; Gira, J.; Berdy, G. J.; Brusatti, R. Safety of Besifloxacin Ophthalmic Suspension 0.6\% as a Prophylactic Antibiotic Following Routine Cataract Surgery: Results Of A Prospective, Parallel-Group, Investigator-Masked Study. Clin. Ophthalmol. 2012, 6, 855-863. doi:10.2147/OPTH.S29604.

[42] World Health Organization, Antimicrobial resistance: Global Report on Surveillance; WHO: Geneva, 2014.

[43] Anastas, P. T.; Warner, J. C. Green Chemistry: Theory and Practice; Oxford University Press: New York, 1998.

[44] Arnold, D. R.; Granvil, C. P.; Ward, K. W.; Proksch, J. W. Quantitative Determination of Besifloxacin, A Novel Fluoroquinolone Antimicrobial Agent, in Human Tears by Liquid Chromatography Tandem Mass Spectrometry. J. Chromatogr. B 2008, 867, 105-110. doi:10.1016/j.jchromb.2008.03.025.

[45] Gu, X.-F.; Mao, B. Y.; Xia, M.; Yang, Y.; Zhang, J.- L.; Yang, D.- S.; Wu, W.- X.; Du, Y.- X.; Di, B.; et al. Rapid, Sensitive And Selective Hplc-Ms/Ms Method for the Quantification of Topically Applied Besifloxacin in Rabbit Plasma and Ocular Tissues: Application to a Pharmacokinetic Study. J. Pharm. Biomed. Anal. 2016, 117, 37-46. doi:10.1016/j.jpba.2015.08.023.

[46] Singh, C. L.; Singh, A.; Santos, B. M.; Ramesh, K. V. Development and Evaluation of Stability Indicating RP-HPLC Method for Analysis of Besifloxacin In Pharmaceutical Formulation. World J. Pharm. Res. 2015, 4, 2057-2067.

[47] Yasaswini, P.; Lakshmi, M. V.; Supraja, M. S.; Sree, M. S.; Suneetha, G. L.; Nalluri, B. N. Development and Validation of New RP-HPLC-PDA Method for the Estimation of Besifloxacin Hydrochloride in Pharmaceutical Dosage Forms. Indo Am. J. Pharm. Res. 2015, 5, 3406-3411.

[48] Domingos, L. C.; Moreira, M. V. L.; Keller, K. M.; Viana, F. A. B. Melo, M. M.; Soto-Blanco, B. Simultaneous Quantification of Gatifloxacin, Moxifloxacin, and Besifloxacin Concentrations in Cornea and Aqueous Humor by LC- QTOF/MS After Topical Ocular Dosing. J. Pharmacol. Toxicol. Methods 2017, 83, 87-93. doi:10.1016/j. vascn.2016.0.

[49] Kumar, G. P.; Srivastava, V.; Khandelwal, K.; Kumar, R.; Hiriyanna, S. G.; Kumar, A.; Kumar, P. Simple Isocratic HPLC Method for Determination of Enantiomeric Impurity in Besifloxacin Hydrochloride. Chirality 2016, 28, 628-632. doi:10.1002/chir

[50] Collins, C. H.; Braga, G. L.; Bonato, P. S. Introdução a métodos cromatográficos 7. ed.; Editora UNICAMP: Campinas, 1997.

[51] Jeffery, R. C.; Basset, G. H.; Mendham, J.; Denney, J. Vogel: Análise química quantitativa; 5 . ed.; LTC Livros Técnicos e Científicos: Rio de Janeiro, 1992.

[52] Ribeiro, R. L. V.; Bottoli, C. B. G.; Collins, K. E.; Collins, C. H. Reevaluation of Ethanol as Organic Modifier for Use in HPLC-RP Mobile Phases. J. Braz. Chem. Soc. 2004, 15, 300-306. doi:10.1590/ S0103-50532004000200022.

[53] Cazedey, E. C. L.; Othman, A.; Garg, S.; Salgado, H. R. N. A Validated Stability-Indicating LC Method for Orbifloxacin in the Presence of Degradation Products. World J. Pharm. Sci. 2011, 7, 176181. doi:10.2174/157341211796353264.

[54] Chierentin, L.; Salgado, H. R. N. Development and Validation of a Simple, Rapid and Stability-Indicating High Performance Liquid Chromatography Method for Quantification of Norfloxacin in a Pharmaceutical Product. J. Chromatogr. Sep. Tech. 2013, 4, 1-5. doi:10.4172/2157-7064.1000171.

[55] Marona, H. R. N.; Zuanazzi, J. A. S.; Schapoval, E. E. S. Determination of Sparfloxacin and its Degradation Products by HPLC-PDA. J. Antimicrob. Chemother. 1999, 44, 301-302. doi:10.1093/jac/44.2.301.

[56] Marona, H. R. N.; Schapoval, E. E. S. A High-Performance Liquid Chromatographic Assay for Sparfloxacin. J. Pharm. Biomed. Anal. 1999, 20, 413-417. doi:10.1016/S0731-7085(98)00102-2.

[57] Chen, J.; Zheng, R.; Ji, S.; Wang, K. Determination of 19 Quinolone Antibiotics in Cosmetics by Ultra-Performance Liquid Chromatography. Chinese J. Anal. Chem. 2013, 6, 931-935.

[58] Ramisetti, N. R.; Arnipalli, M. S.; Nimmu, N. V.; Bondigalla, R UHPLC Determination of Besifloxacin Enantiomers on Immobilized 
Amylose Tris (3, 5- dichlorophenylcarbamate) Chiral Stationary Phase. Chromatographia 2017, 80, 1509-1515. doi:10.1007/s10337017-3346-7.

[59] Nováková, L.; Matysová, L.; Solich, P. Advantages of Application Of UPLC in Pharmaceutical Analysis. Talanta 2006, 68, 908-918. doi:10.1016/j.talanta.2005.06.035.

[60] Tótoli, E. G.; Salgado, H. R. N. Development, Optimization, and Validation of a Green and Stability-Indicating HPLC Method for Determination of Daptomycin in Lyophilized Powder. J. AOAC Int. 2015, 98, 1276-1285. doi:10.5740/jaoacint.15-039.

[61] Singh, C. L.; Singh, A.; Kumar, S.; Kumar, M.; Sharma, P. K.; Majumdar, D. K. Development and Validation of Different Ultraviolet Spectrophotometric Methods for the Estimation of Besifloxacin in Different Simulated Body Fluids. Indian J. Pharm. Sci. 2015, 77, 399-404. doi:10.4103/0250-474X.164784.

[62] Moreno, A. H.; Salgado, H. R. N. Rapid and Selective UV Spectrophotometric Method for the Analysis Of Ceftazidime. J. AOAC Int. 2009, 92, 820-823.

[63] Fiorentino, F. A. M.; Salgado, H. R. N. Development and Validation of a UV-Spectrophotometric Method for Determination of Flucloxacillin Sodium in Capsules. Curr. Pharm. Anal. 2012, 8, 101-106. doi:10.2174/157341212798995485.

[64] Silva, L. M.; Almeida, A. E.; Salgado, H. R. N. Thermal Analysis and Validation of UV and Visible Spectrophotometric Methods for the Determination of New Antibiotic Tigecycline in Pharmaceutical Product. Adv. Anal. Chem. 2012, 2, 10-15.

[65] Pedroso, T. M.; Salgado, H. R. N. Validation of Cefazolin Sodium by UV-Spectrophotometric Method. Phys. Chem. 2013, 3, 11-20.

[66] Tótoli, E. G.; Salgado, H. R. N. A Green Approach for the Quantification of Daptomycin in Pharmaceutical Formulation by UV Spectrophotometry. Brazilian J. Pharm. Sci. 2015, 51, 811-821. doi:10.1590/ S1984-82502015000400007.

[67] Cazedey, E. C. L.; Bonfilio, R.; Araújo, M. B.; Salgado, H. R. N. A First-Derivative Spectrophotometric Method For The Determination of Ciprofloxacin Hydrochloride in Ophthalmic Solution. Phys. Chem. 2013, 2, 116-122. doi:10.5923/j. pc.20120206.06.

[68] Chierentin, L.; Salgado, H. R. N. Performance Characteristics of UV and Visible Spectrophotometry Methods for Quantitative Determination of Norfloxacin In Tablets. J. Sci. Res. 2014, 6, 531-541. doi:10.3329/jsr.v6i3.18381.

[69] Natori, J. S. H.; Tótoli, E. G.; Salgado, H. R. N. Development and Validation of a Green Analytical Method for the Determination of Norfloxacin in Raw Material by FTIR Spectrophotometry. J. AOAC Int. 2016, 99, 1533-1536. doi:10.5740/jaoacint.16-0177.

[70] Cazedey, E. C. L.; Salgado, H. R. N. Development and Validation of UV Spectrophotometric Method for Orbifloxacin Assay and Dissolution Studies. Brazilian J. Pharm. Sci. 2014, 50, 457-466. doi:10.1590/ S1984-82502014000300003.

[71] Gomes, G. C.; Salgado, H. R. N. Validation of UV Spectrophotometric Method for Determination of Lomefloxacin in Pharmaceutical Dosage Form. Acta Farm. Bonaer. 2005, 24, 406-408.
[72] Salgado, H. R. N.; Oliveira, C. Development and Validation Of an UV Spectrophotometric Method for Determination of Gatifloxacin in Tablets. Die Pharm. 2005, 60, 263-264.

[73] Marona, H. R. N.; Schapoval, E. E. S. Spectrophotometric Determination of Sparfloxacin in Tablets. J. Antimicrob. Chemother. 1999, 44, 136-137. doi:10.1093/jac/44.1.136.

[74] Marona, H. R. N.; Schapoval, E. E. S. Spectrophotometric Determination of Sparfloxacin in Pharmaceutical Formulations Using Bromothymol Blue. J. Pharm. Biomed. Anal. 2001, 26, 501-504. doi:10.1016/S0731-7085(01)00429-0.

[75] Cazedey, E. C. L.; Salgado, H. R. N. Development and Validation of a Microbiological Agar Assay for Determination of Orbifloxacin in Pharmaceutical Preparations. Pharmaceutics 2011, 3, 572-581. doi:10.3390/pharmaceutics3030572.

[76] Cazedey, E. C. L.; Salgado, H. R. N. A Novel and Rapid Microbiological Assay for Ciprofloxacin Hydrochloride. J. Pharm. Anal. 2013, 3, 382-386. doi:10.1016/j.jpha.2013.03.007.

[77] Chierentin, L.; Salgado, H. R. N. Development and Validation of a Rapid Turbidimetric Assay to Determine the Potency of Norfloxacin in Tablets. Brazilian J. Pharm. Sci. 2015, 51, 629-635. doi:10.1039/c3ay40847g.

[78] Marona, H. R. N.; Schapoval, E. E. S. Desarrollo de análisis microbiológico para la determinación de esparfloxacino en polvo y en comprimidos de $200 \mathrm{mg}$. Inf. Tecnol. 1998, 9, 251-254.

[79] Marona, H. R. N.; Schapoval, E. E. S. Analysis of Sparfloxacin and its Degradation Products by Bioassay. Acta Pharm. Turcica 2001, 43, 7-9.

[80] Marona, H. R. N.; SchapovaL, E. E. S. Performance Characteristics of Bioassay, Nonaqueous Titration, UV-Spectrophotometry and High Performance Liquid Chromatographic Determination of Sparfloxacin in Tablets. Braz. J. Pharm. Sci. 2001, 37, 171-175.

[81] Moreno, A. H.; Salgado, H. R. N. Microbiological Assay for Ceftazidime Injection. J. AOAC Int. 2007, 90, 1379-1382.

[82] Tótoli, E. G.; Salgado, H. R. N. Rapid Turbidimetric Assay to Determine the Potency of Daptomycin in Lyophilized Powder. Pharmaceutics 2015, 7, 106-121. doi:10.3390/pharmaceutics7030106.

[83] Attia, A. K.; Badawy, M.; Abd-Elhamid, S. G. Determination of Sparfloxacin and Besifloxacin Hydrochlorides Using Gold Nanoparticles Modified Carbon Paste Electrode in Micellar Medium. RSC Adv., 2016, 6, 39605-39617. doi:10.1039/C6RA04851J.

[84] Marona, H. R. N.; Schapoval, E. E. S. Development and Validation of a Nonaqueous Titration with Perchloric Acid to Determine Sparfloxacin in Tablets. Eur. J. Pharm. Biopharm. 2001, 52, 227-229. doi:10.1016/S0939-6411(01)00177-1.

[85] Marona, H. R. N.; Lopes, C. C. G. O.; Cardoso, S. G. Non-aqueous Titration Of Gatifloxacin in Pharmaceutical Formulations Using Perchloric Acid. Latin Am. J. Pharm. 2003, 22, 339-342.

[86] Alsante, K. M.; Ando, A.; Brown, R.; Ensing, J.; Hatajik, T. D.; Kong, W.; Tsuda, Y. The Role of Degradant Profiling in Active Pharmaceutical Ingredients and Drug Products. Adv. Drug Deliv. Rev. 2007, 59, 29-37. doi:10.1016/j.addr.2006.10.006.

[87] Blessy, M.; Patel, R. D.; Prajapati, P. N.; Agrawal, Y. K. Development of Forced Degradation and Stability Indicating Studies of Drugs - A Review. J. Pharm. Anal. 2014, 4, 159-165. doi:10.1016/j.jpha.2013.09.003. 